\title{
A retrospective analysis of the start of the COVID-19 epidemic in Canada, January 15- March 12, 2020
}

\author{
Public Health Agency of Canada COVID-19 Surveillance and Epidemiology Team ${ }^{1}$
}

\begin{abstract}
We describe the epidemiology of COVID-19 at the start of Canada's epidemic from January 1 to March 12, 2020, before governments at all levels implemented aggressive communitybased public health measures. During this time, 153 laboratory-confirmed cases were reported in Canada. Due to delays inherent in the diagnosis and reporting process, these cases represented a small subset of the 1,360 confirmed cases subsequently reported, whose symptom onset occurred on or before March 12. More than half (57.8\%) of these 1,360 cases had a history of international travel or were linked to a case that had travelled, most commonly from countries where few cases had been reported at that time. Community transmission, marked by cases that could not be traced back to another case, was first noted on February 20 and increased steadily thereafter. This descriptive analysis indicates that COVID-19 was spreading internationally and in Canada more broadly than was initially detected by surveillance systems from January to mid-March 2020. To limit the impact of future waves, an expanded surveillance system is now being implemented with multiple data streams to provide a more complete picture of the epidemic, including early signals of cases and clusters. Improved access to laboratory testing and expanded contact tracing are critical elements to detect and isolate cases early, including those with mild symptoms.
\end{abstract}

This work is licensed under a Creative Commons Attribution 4.0 International License.

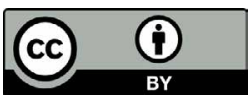

Affiliation

${ }^{1}$ Public Health Agency of Canada, Ottawa, ON

*Correspondence:

lindsay.whitmore@canada.ca

Suggested citation: Public Health Agency of Canada COVID-19 Surveillance and Epidemiology Team. A retrospective analysis of the start of the COVID-19 epidemic in Canada, January 15-March 12, 2020. Can

Commun Dis Rep 2020;46(7/8):236-41. https://doi.org/10.14745/ccdr.v46i78a04

Keywords: epidemic, COVID-19, Canada, retrospective analysis, epidemiology

\section{Introduction}

Following reports of severe pneumonia with an unknown etiology in Wuhan, China in December 2019 and subsequent confirmation that these illnesses were caused by a novel coronavirus on January 7, 2020, the federal, provincial, territorial and local governments in Canada implemented enhanced public health surveillance and took progressive public health action to prevent transmission of the disease inside their borders. These efforts included, and were not limited to, activating intergovernmental public health emergency response plans, implementing progressively more restrictive border measures, and establishing and expanding testing capacity. Early efforts focussed on containment at source, in order to slow importation to Canada and prevent spread domestically.

Canada's first imported case was reported on January 25, 2020 but it was not until mid-March that daily case counts started climbing. By June 2, 92,151 cases had been reported across 12 provinces and territories. Though daily case counts were on the decline at the time of writing, the disease continues to spread in some areas and settings, and no vaccine currently exists for this novel coronavirus. Evidence-based public health measures are vital to control the epidemic in Canada. Understanding the early epidemiology of COVID-19 in Canada will inform the strengthening of public health surveillance systems, allow for the implementation of appropriate public health measures, and increase understanding of impacts across different groups (e.g. women and men, different age groups).

This rapid communication describes the epidemiology of COVID-19 in Canada from January 1 to March 12, 2020.

March 12, 2020 is significant because this date marks the beginning of aggressive public health measures implemented by federal, provincial and territorial jurisdictions to limit the transmission of COVID-19 (e.g. school closures, closure of non-essential businesses and strict border controls) in Canada. 


\section{Situation}

\section{Importation}

Based on information received from provinces and territories as of April 17, 2020, 1,360 laboratory-confirmed cases were reported with an illness onset between January 1 and March 12, 2020. Case characteristics are summarised in Table 1, including cases by sex and age. During this period, more than half $(57.8 \%)$ of the cases were related to international travel: $52.2 \%(n=710)$ had a history of international travel and $5.6 \%$ $(n=76)$ were linked to cases who had travelled. Of the 710 cases with a history of international travel, 703 cases provided specific information on countries visited. More than a third (34.7\%) of these cases had transited through or arrived from the United States, and almost $20 \%$ had arrived from either the United Kingdom or France (Table 2). Notably, only $1.4 \%$ of cases had arrived from China even though China was the epicenter of the COVID-19 pandemic throughout January and February $(1,2)$.

Table 1: Characteristics of COVID-19 cases with illness onset from January to March 12, 2020 ( $N=1,360)$

\begin{tabular}{|c|c|c|}
\hline \multirow{2}{*}{$\begin{array}{c}\text { Case } \\
\text { characteristics }\end{array}$} & \multicolumn{2}{|c|}{ Frequency } \\
\hline & $n$ & $\%$ \\
\hline \multicolumn{3}{|l|}{ Province/territory } \\
\hline ON & 533 & 39.2 \\
\hline $\mathrm{QC}$ & 312 & 22.9 \\
\hline$B C$ & 250 & 18.4 \\
\hline$A B$ & 166 & 12.2 \\
\hline MB & 24 & 1.8 \\
\hline NS & 18 & 1.3 \\
\hline NB & 17 & 1.3 \\
\hline SK & 32 & 2.4 \\
\hline NL & 1 & 0.1 \\
\hline PE & 2 & 0.2 \\
\hline YT & 2 & 0.2 \\
\hline Repatriated traveller & 3 & 0.2 \\
\hline \multicolumn{3}{|l|}{ Gender $^{b}$} \\
\hline Female & 670 & 49.5 \\
\hline Male & 684 & 50.5 \\
\hline \multicolumn{3}{|l|}{ Age group (years) } \\
\hline $0-19$ & 52 & 3.9 \\
\hline $20-39$ & 368 & 27.8 \\
\hline $40-59$ & 510 & 38.5 \\
\hline $60-79$ & 341 & 25.8 \\
\hline 80 and older & 53 & 4.0 \\
\hline $\begin{array}{l}\text { Hospitalized } \\
\text { (includes ICU) }\end{array}$ & 195 & 17.5 \\
\hline ICU admissions & 81 & 10.3 \\
\hline Deaths & 27 & 2.5 \\
\hline
\end{tabular}

Abbreviations: AB, Alberta; BC, British Columbia; ICU, intensive care unit; MB, Manitoba; NB, New Brunswick; NL, Newfoundland and Labrador; NS, Nova Scotia; ON, Ontario; PE, Prince Edward Island; QC, Quebec; SK, Saskatchewan; YT, Yukon Territory a Missing data for gender (six cases), age (36 cases), hospitalized (246 cases), ICU admissions (573 cases) and deceased (280 cases) were not included in the calculation of percentages

b Provinces and territories may define gender differently and some may be referring to biological sex
Table 2: Countries visited by cases of COVID-19 in Canada who reported international travel in 14 days prior to symptom onset, January to March 12, 2020 $(\mathrm{N}=703)$

\begin{tabular}{|c|c|c|}
\hline Country(ies) ${ }^{a, b}$ & n & $\%$ \\
\hline United States & 244 & 34.7 \\
\hline United Kingdom & 67 & 9.5 \\
\hline France & 64 & 9.1 \\
\hline International conveyance (cruise) & 47 & 6.7 \\
\hline Germany & 45 & 6.4 \\
\hline Mexico & 35 & 5.0 \\
\hline Iran & 34 & 4.8 \\
\hline Egypt & 33 & 4.7 \\
\hline Spain & 29 & 4.1 \\
\hline Switzerland & 24 & 3.4 \\
\hline Austria & 22 & 3.1 \\
\hline Portugal & 21 & 3.0 \\
\hline Philippines & 20 & 2.8 \\
\hline Cuba & 19 & 2.7 \\
\hline The Netherlands & 19 & 2.7 \\
\hline Italy & 17 & 2.4 \\
\hline China & 10 & 1.4 \\
\hline
\end{tabular}

Cases that travelled were categorized according to World Health Organization (WHO) region(s) (3) visited to examine trends over time (Figure 1). In the first three weeks of the epidemic (weeks of January 12 to January 26, 2020), there were seven cases and all were either travellers arriving from China (Western Pacific Region) or their close contacts. In early February, four cases were reported with a travel history to the Eastern Mediterranean Region, the European Region and the Americas. Cases with a travel history from these regions occurred despite small numbers of cases being reported within these regions at the time [nine cases in the Eastern Mediterranean Region, 46 cases in the European region and 15 cases in the Americas (excluding Canada)] (4). In the last two weeks of February, a total of 99 cases had transited through or arrived from countries in the Americas. This occurred despite a total of only 65 cases reported within countries of the Americas (excluding Canada) by the end of February (2).

A number of border and travel health measures were implemented during this period (i.e. travel health notices, enhanced symptom screening and public health messaging at ports of entry and requesting arriving international travellers from certain jurisdictions to self-isolate for 14 days). The implementation of measures specific to individual countries was guided, in part, by the number of COVID-19 cases and the type of transmission that was reported by the $\mathrm{WHO}$ and individual 
Figure 1: Laboratory-confirmed COVID-19 cases in Canada by date of illness onset and region of travel for cases reporting international travel, January 15 to March 12, $2020(\mathrm{~N}=1,275)$

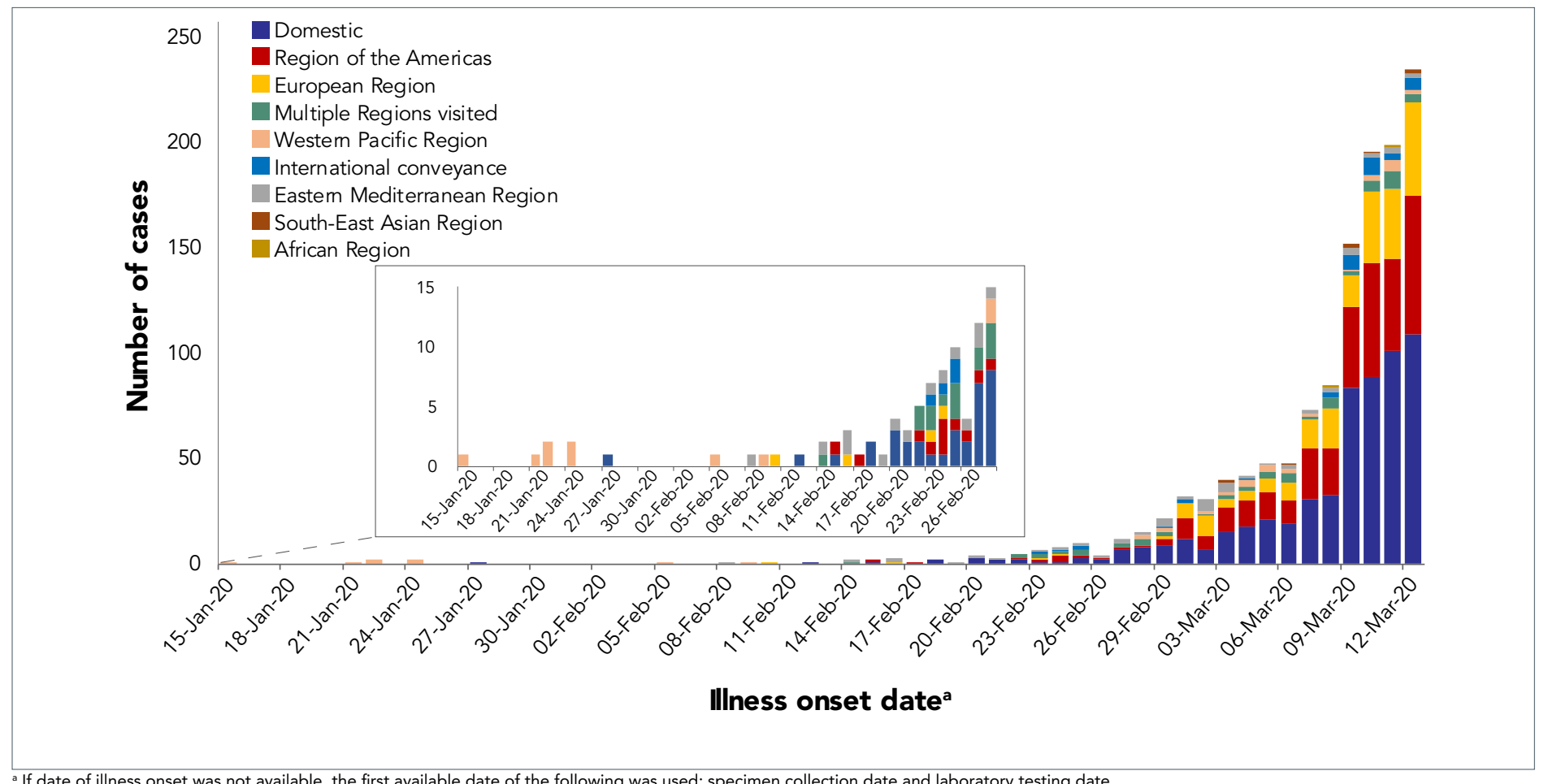

If date of illness onset was not available, the first available date of the following was used; specimen collection date and laboratory testing date

countries. The type of transmission was categorized by the WHO as imported cases only, local transmission (transmission occurred within the country with few cases not related to known chains of transmission) or community transmission, defined as the inability to relate a large number of confirmed cases to chains of transmission (2). At the time, with the exception of China, all imported cases to Canada were from countries assessed by WHO as countries with imported cases only or local transmission with no community transmission. In retrospect, it is clear that what was reported globally was only the tip of the iceberg and that the true extent of the global spread of the disease was not known at the time. Using lessons learned from the first wave of COVID-19, additional data sources and indicators will be included in the risk assessments that are used to inform various border and travel health measures such as the timely posting of travel health notices.

\section{Early detection}

Early detection of cases is vital to implementing effective public health measures at all jurisdictional levels (local, provincial, territorial and federal). During the start of the epidemic, the median number of days between illness onset and case report date (as noted by local public health) differed significantly by type of exposure $(p<0.05)$. Cases linked to international travel and those that were linked with a known case had a slightly lower number of median days between illness onset and reporting compared to cases that could not be linked to a known case (Table 3). In other countries, differences have been noted between those whose infections were acquired internationally compared to domestically $(5,6)$. These differences in Canada and elsewhere were likely due to a higher index of suspicion for those with risk factors that were known at the time. The number of days between illness onset and case report date increased over time, as the number of cases that could not be linked to other cases also increased. This delay began to decrease for cases with illness onset in early March (Figure 2).

Table 3: Number of days between date of illness onset and case report date $(\mathrm{N}=727)^{a}$

\begin{tabular}{|l|r|r|r|r|}
\hline \multicolumn{1}{|c|}{$\begin{array}{c}\text { Exposure } \\
\text { category }\end{array}$} & $\mathbf{n}$ & $\begin{array}{c}\text { Median } \\
\text { number of } \\
\text { days }\end{array}$ & $\begin{array}{c}2^{\text {th }} \\
\text { percentile }\end{array}$ & \multicolumn{1}{|c|}{$\begin{array}{c}\mathbf{7 5}^{\text {th }} \\
\text { percentile }\end{array}$} \\
\hline $\begin{array}{l}\text { International travel } \\
\text { history }\end{array}$ & 400 & 9 & 6 & 15 \\
\hline $\begin{array}{l}\text { Domestically } \\
\text { acquired_Linked to } \\
\text { a traveller }\end{array}$ & 49 & 7 & 5 & 11.5 \\
\hline $\begin{array}{l}\text { Domestically } \\
\text { acquired_Linked to } \\
\text { a domestic case }\end{array}$ & 134 & 8 & 6 & 18 \\
\hline $\begin{array}{l}\text { Domestically } \\
\text { acquired-Could not } \\
\text { be linked }\end{array}$ & 87 & 11 & 10 & 19 \\
\hline $\begin{array}{l}\text { Domestic-Contact } \\
\text { information not } \\
\text { specified }\end{array}$ & 57 & 11 & & 14 \\
a Dates needed to calculate days from illness onset to case report date were missing for 633 \\
(46.5\%) cases
\end{tabular}


Figure 2: Number of days between illness onset date and case report date (seven day moving average) for COVID-19 cases by exposure, January 15 to March 12, $2020(\mathrm{~N}=727)$

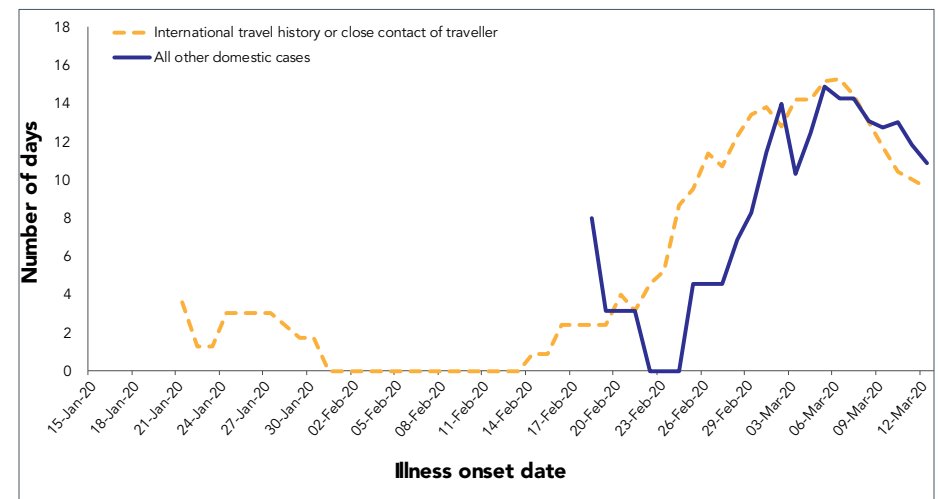

At the provincial, territorial and federal levels, timely information on cases is needed to develop, implement and evaluate programs and policies to limit transmission. Due to the length of time between illness onset and reporting of cases, provinces and territories had only reported 153 COVID-19 cases as of March $12^{\text {th }}$, compared to the 1,360 laboratory confirmed cases with actual illness onset during this period (see Figure 3). As well, there were likely unreported infections during this period due to limited testing at the time. Results from some countries have indicated the disease was already spreading before the rapid rise in cases was apparent and noted, or in the case of France, even before the first case was reported $(7,8)$.

Figure 3: Number of COVID-19 cases reported daily by provinces and territories compared with those with illness onset ${ }^{a}$, January 15 to March 12, 2020

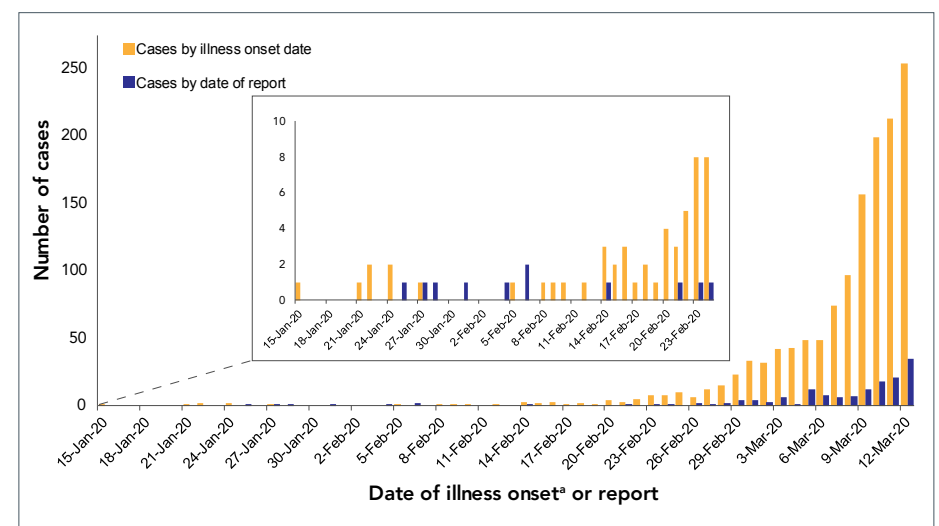

a If date of illness onset was not available, the earliest available date of the following was used: specimen collection date and laboratory testing date

At the start of the epidemic, public health surveillance efforts were informed by the surveillance guidance within the Canadian Pandemic Influenza Plan (9). For example, in the initial stages of Canada's epidemic, detailed information was captured on confirmed cases (10) to allow for a description of the epidemiological characteristics of the cases. These efforts were complemented by provincial and territorial efforts, including enhanced surveillance in certain settings (e.g. testing of individuals with respiratory illness in hospitals). Moving forward, a number of complementary data streams will be integrated, to help strengthen COVID-19 monitoring efforts at the national level and detect early signals of increases in cases or clusters or changes in disease severity. These data streams are expected to include provincial and territorial case-based information, federal and provincial public health laboratory data; hospital, emergency and outpatient data, outbreak information and syndromic surveillance through the "Fluwatchers" app (11), among other data sources. The results of future studies will be used to build on the information gleaned from these surveillance activities, and will provide more detailed information on key populations (e.g. the impact of COVID-19 on racialized communities, health care workers, Indigenous communities, and different groups of women, men and gender diverse people).

\section{Onward transmission}

In the first four weeks of Canada's outbreak (weeks of January 12 to February 2), $100 \%$ of the cases were related to travel (had travelled, or were linked to a traveller). From the week of February 9 to March 12 between $11 \%$ and $40 \%$ of cases, by week, were domestic cases that could be traced back to another domestic case. On February 23, the first case became ill who could not be linked to another known case (an indicator of community transmission), after which the number of such cases grew steadily (Figure 4). Other countries have similarly experienced a short phase of mostly imported cases, followed by the onset and exponential growth in domestically acquired cases (12).

To prevent onward transmission, at the start of the epidemic, guidelines on infection prevention and control and on public health management of cases and contacts were disseminated to facilities and to public health professionals. Canadians were urged to self-monitor for symptoms, to stay at home when ill and practice frequent and meticulous hygienic measures. Nonetheless, community transmission occurred and the number of such cases increased rapidly. This may reflect a number of factors: Canada was still in its influenza season and individuals may not have sought out testing if they had influenza-like symptoms; the contribution of transmission from individuals with mild symptoms who did not seek out testing or who did not qualify for testing given the testing guidance in place at the time; or transmission from individuals who were pre or asymptomatic (13). 
Figure 4: Laboratory-confirmed cases of COVID-19 in Canada by date of illness onset and exposure category, January 15 to March 12, $2020(\mathrm{~N}=1,276)$

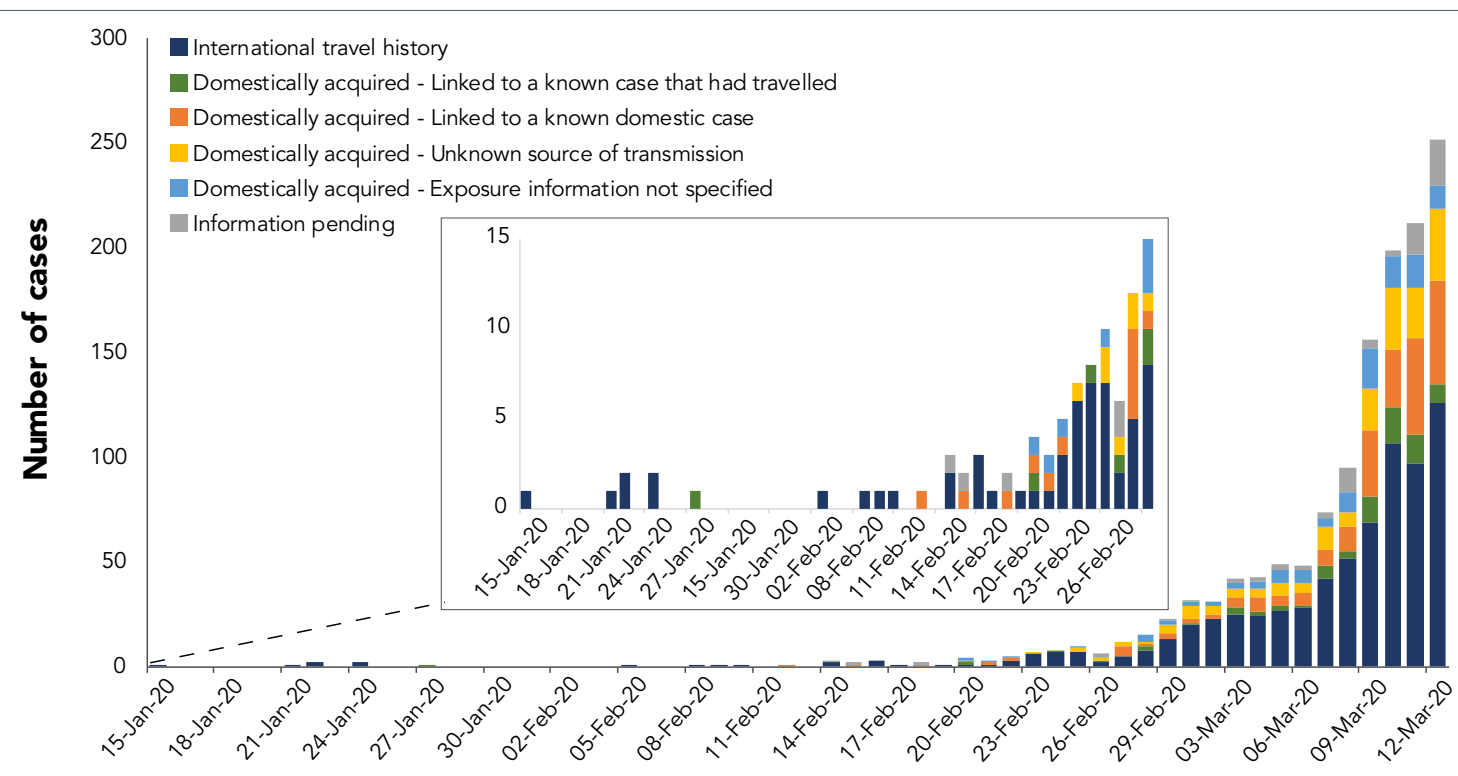

Illness onset date ${ }^{a}$

a If date of illness onset was not available, the earliest available date of the following was used: specimen collection date and laboratory testing date

\section{Conclusion}

At the start of Canada's epidemic, public health measures to limit the spread of COVID-19 were guided, in part, by the epidemiologic data available at the time. In hindsight, it is clear that these data did not provide the full picture in relation to when and where the disease had spread or how and when individuals were capable of spreading the infection to others. As new evidence emerged to expand our knowledge of COVID-19 epidemiology, our case detection protocols, public health measures and other areas of the COVID-19 response were adapted. Moving forward, surveillance systems will likewise continue to be enhanced through the addition of numerous data streams, which will allow for a more complete picture of the epidemiology of COVID-19 and for the early detection of cases and clusters to inform public health action and improved management of COVID-19 in Canada.

\section{Authors' statement}

DP - Conceptualization, original draft, review and editing

$\mathrm{LL}$ - Data curation, formal analysis, review and editing

LW - Review and editing

AC - Conceptualization, review and editing

$\mathrm{KW}$ - Review and editing

$\mathrm{MB}$ - Review and editing

DT - Review and editing

CA - Review and editing

JT - Data curation, formal analysis
JZ - Data curation, formal analysis

JK - Data curation, formal analysis

DM - Review and editing

AN - Review and editing

JP - Review and editing

\section{Competing interests}

None.

\section{Acknowledgements}

Authors wish to thank provincial and territorial surveillance partners, the National Microbiology Laboratory and provincial public health laboratory partners, and the Health Portfolio Operations Centre's Surveillance Team, Public Health Agency of Canada.

Public Health Agency of Canada COVID-19 Surveillance and Epidemiology Team includes: Dana Paquette, Liza Lee, Lindsay Whitmore, Andrea Currie, Kerri Watkins, Maggie Bryson, Dorcas Taylor, Chris Archibald, Jill Tarasuk, Jingxuan Zhang, Jaskiran Kaur, Diane MacDonald, Alexandra Nunn, Jennifer Pennock.

\section{Funding}

This work was supported by Public Health Agency of Canada. 


\section{References}

1. World Health Organization. Novel Coronavirus (2019nCoV) Situation Report - 1: 21 January 2020. Geneva (CH): WHO (accessed 2020-05-19). https://www.who.int/docs/ default-source/coronaviruse/situation-reports/20200121sitrep-1-2019-ncov.pdf?sfvrsn=20a99c10_4

2. World Health Organization. Novel Coronavirus (2019-nCoV) Situation Report - 40: February 29, 2020. Geneva (CH): WHO (accessed 2020-05-19). https://www.who.int/docs/ default-source/coronaviruse/situation-reports/20200229sitrep-40-covid-19.pdf?sfvrsn=849d0665_2

3. World Health Organization. WHO Regional Offices (accessed 2020-05-19). https://www.who.int/about/who-we-are/ regional-offices

4. World Health Organization. Novel Coronavirus (2019-nCoV) Situation Report - 26: 15 February 2020. Geneva (CH): WHO (accessed 2020-05-19). https://www.who.int/docs/ default-source/coronaviruse/situation-reports/20200215sitrep-1-2019-ncov.pdf?sfvrsn=20a99c10_4

5. Spiteri G, Fielding J, Diercke M, Campese C, Enouf V, Gaymard A, Bella A, Sognamiglio P, Sierra Moros MJ, Riutort AN, Demina YV, Mahieu R, Broas $M$, Bengnér $M$, Buda S, Schilling J, Filleul L, Lepoutre A, Saura C, Mailles A, Levy-Bruhl D, Coignard B, Bernard-Stoecklin S, Behillil S, van der Werf S, Valette M, Lina B, Riccardo F, Nicastri E, Casas I, Larrauri A, Salom Castell M, Pozo F, Maksyutov RA, Martin C, Van Ranst M, Bossuyt N, Siira L, Sane J, Tegmark-Wisell K, Palmérus $M$, Broberg EK, Beauté, Jorgensen $P$, Bundle N, Pereyaslov D, Adlhoch C, Pukkila J, Pebody R, Olsen S, Ciancio BC. First cases of coronavirus disease 2019 (COVID-19) in the WHO European Region, 24 January to 21 February 2020. Euro Surveill 2020;25(9):2000178.

DOI PubMed

6. Kwok KO, Wong VW, Wei WI, Wong SY, Tang JW. Epidemiological characteristics of the first 53 laboratory-confirmed cases of COVID-19 epidemic in Hong Kong, 13 February 2020. Euro Surveill 2020;25(16):2000155. DOI PubMed
7. Valenti L, Bergna A, Pelusi S, Facciotti F, Lai A, Tarkowski M, Berzuini A, Caprioli F, Santoro L, Basellli G, Ventura CD, Erba E, Bosari S, Galli M, Zehender G, Prati D. SARS-CoV-2 seroprevalence trends in healthy blood donors during the COVID-19 Milan outbreak. https://www.medrxiv.org/content /10.1101/2020.05.11.20098442v1.full.pdf

8. Deslandes A, Berti V, Tandjaoui-Lambotte Y, Alloui C, Carbonnelle E, Zahar JR, Brichler S, Cohen Y. SARS-CoV-2 was already spreading in France in late December 2019. Int J Antimicrob Agents 2020;55(6):106006. DOI PubMed

9. Pan-Canadian Public Health Network. Canadian Pandemic Influenza Preparedness: Planning Guidance for the Health Sector, Surveillance Annex. Ottawa (ON): PHAC; December 3, 2015 (accessed 2020-05-19). https://www.canada.ca/ content/dam/phac-aspc/migration/phac-aspc/cpip-pclcpi/ assets/pdf/annex_n-eng.pdf

10. Government of Canada. Interim national surveillance guidelines for human infection with Coronavirus disease (COVID-19). Ottawa (ON): Government of Canada (modified 2020-02-10; accessed 2020-05-21). https://www.canada.ca/ en/public-health/services/diseases/2019-novel-coronavirusinfection/health-professionals/interim-guidanc e-surveillance-human-infection.html

11. Government of Canada. Fluwatchers. Ottawa (ON): Government of Canada (modified 2020-03-31; accessed 2020-05-27). https://www.canada.ca/en/public-health/ services/diseases/flu-influenza/fluwatcher.html

12. Weber A, lannelli F, Goncalves S. Trend analysis of the COVID-19 pandemic in China and the rest of the world. https://arxiv.org/pdf/2003.09032.pdf

13. Hu Z, Song $C, X u C$, Jin $G$, Chen $Y, X u X, M a H$, Chen W, Lin $Y$, Zheng $Y$, Wang J, Hu Z, Yi Y, Shen H. Clinical characteristics of 24 asymptomatic infections with COVID-19 screened among close contacts in Nanjing, China. Sci China Life Sci 2020 May;63(5):706-11. DOI PubMed 